\title{
The Right to Quality Education for Refugee Children Through Social Inclusion
}

\author{
Rebecca Leela Thomas ${ }^{1}$
}

Published online: 7 December 2016

C) Springer International Publishing 2016

\begin{abstract}
The number of refugees worldwide has increased exponentially in recent years, and children represent more than half of the refugee population. The needs of refugee children are complex. Many have traumatic experiences and disrupted education, and are then tasked with adapting to a new culture. The literature emphasizes the importance of education in determining the future of young refugees and its potential to transform lives for those who have access to it. This article will focus on the right to education and social inclusion of refugee children in the school system from a human rights perspective. The author proposes that schools play a critical role in helping refugee children find some sense of safety and helping maximize their learning potential. This human rights and social inclusion approach requires active participation from government, school administration, the ESL and mainstream teachers, the social workers, students and their parents, refugee students and their parents, and the community to partner together to create an environment for active learning and socialization for productive citizenry in the USA. The author maintains that social work is in a unique position and suggests strategies that facilitate a broader effort toward social inclusion which is vital to the well-being of refugee children and allows them to become an integral part of society.
\end{abstract}

Keywords Human rights $\cdot$ Refugee children $\cdot$ Schools · Education $\cdot$ Social inclusion $\cdot$ Learning $\cdot$ Language $\cdot$ Trauma . Resettlement

Rebecca Leela Thomas

rlthomas@uconn.edu

1 UConn School of Social Work, West Hartford, CT, USA
Globally each year, millions of individuals and families flee their native countries to find safety in other nation states. They escape because their governments will not or cannot protect them against human rights abuses. These refugees have a legitimate fear of being persecuted because of race, religion, nationality, political opinion, or membership in a particular social group. The United Nations Refugee Convention signed in 1951 defines a refugee as a person who, because of fear and persecution, leaves their country of nationality and is unable or unwilling to access for himself the protection of that country (United Nations 2016). Resettlement in another country "provides a durable solution for refugees unable to voluntarily return home or remain in their country of refuge" (United Nations High Commission for Refugees (UNHCR), United Nations Development Program 2015, p.46).

Presently, the refugee crisis is at an all-time high since World War II. Due to civil war, violence, persecution, environmental disasters, poverty, and food scarcity, the number of refugees worldwide has increased exponentially. Each day, 42,500 people leave their homes to seek protection from conflict and persecution. They settle either within their countries' borders or in other nations (United Nations 2016). Approximately half of all refugees are children under the age of 18 (Save the Children 2016; United Nations 2016) and all have the right to quality education.

For many refugee children, this new identity in a new culture is often associated with past traumas. In addition to the traumatic transition in a new environment, many refugee children have to cope with trauma from past experiences and the impact of displacement. They have experienced traumas such as disruption of their daily lives, the loss of their home countries, separation from their families, and food scarcity. Many have witnessed violence and death. The very nature of being a 
refugee implies having one's life - including one's cultural environment - upended. It implies a transitory lifestyle in which there exists a great deal of uncertainty (Lerner 2012).

The application for refugee status is a rigorous process, especially in the United States (US), and it is extremely stressful for children. The initial trauma, the eventual move to safety, and the resettlement in a new country each bring different challenges (Fazel and Stein 2002). Many refugee children bring these past experiences and mental health issues with them into the school environment. Sirin and Rogers-Sirin (2015) found that almost half of the surveyed Syrian youth refugees experienced symptoms of PTSD. Refugee children, and their parents, have experienced unimaginable losses; many of them have actually witnessed the destruction of their homes and communities, and the injuries and deaths of friends and family. Often they have made a rapid descent into poverty, leaving everything they owned behind (Meda, Sookrajh and Maharaj 2012). Their entire way of life destroyed, flight to another country is the only option. Once they cross an international border, they find themselves detained, often for years, in refugee camps where years of school can be lost altogether. Sidhu and Taylor (2012) point out that prolonged periods in refugee camps may have devastating effects on their educational levels. In the US, they are often placed in lower grades that are not age-appropriate, causing more social isolation and humiliation.

Education in resettlement for refugee children has other challenges as well. They arrive at odd times during the school year with no records of their academic histories, upsetting teachers who are taken aback at their sudden appearance in the classroom. Many of those teachers feel resentful about the extra responsibility of teaching them (Bacakova 2011). Understandably, the statistics on school dropouts for refugees are also not very good. They tend to fall behind, and $25 \%$ of those who are foreign-born drop out of school altogether (Kugler 2009). Refugee children are also victims of bullying in the schools. Hart (2009) describes how many refugee children start out believing that the time before their flight from home was a period of "persecution and danger," and that the time after their arrival would be a "safe haven," only to discover that in resettlement, they are not safe at school and feel threatened by their peers (354-355). Such impediments make assimilation, and therefore quality education, more difficult to attain.

Human Rights Watch (HRW 2015) emphasizes the importance of education in determining the futures of young refugees and its potential to transform lives of those who are able to access it. The United Nations High Commissioner for Refugees (UNHCR) refers to education as "a right through which other rights are realized" (UNHCR p.18). Since education has rehabilitative and restorative properties, it can lead to positive outcomes for individuals, families, communities, and societies. Furthermore, UNHCR underscores that education is a human right to be realized and cultivated in any situation, even when refugees are in crises (UNHCR 2011, p. 9). Thus, education is not a luxury to be put on hold during times of displacement but an essential component of life for refugee children. Since refugees are often on the move, the effects of their access to education are far-reaching. "The quality of education refugee children receive in exile determines their ability to contribute to their home and host societies" (UNHCR p. 8). This report emphasizes that education is often a primary concern of refugee families - "The provision of educational opportunities is one of the highest priorities of refugee communities" (UNHCR 2011, p. 8). For many refugees, the USA is and has been a beacon of hope to begin a life with new opportunities, including access to an inclusive learning environment.

This article will focus on the right to education and social inclusion of refugee children in the US school system from a human rights perspective. The concept of social inclusion (Lyons and Huegler 2012) was defined in 1995 as "the capacity of people to live together with full respect for the dignity of each individual, the common good, pluralism and diversity, non-violence and solidarity, as well as their ability to participate in social, cultural, economic and political life" (UN 1995, p. 39). The World Bank (2013) underscored that social inclusion is both an outcome and a process of improving the terms on which people take part in society. The author proposes that schools play a critical role in helping refugee children find some sense of safety and helps maximize their learning potential. This human rights emphasizes a social inclusion approach that requires active participation from government, school administration, the ESL teachers, teachers, the school social worker, students and their parents, refugee students and their parents, and the community. Ideally, these forces would partner together to create an environment for active learning and socialization for productive citizenry in the US.

Social workers are in a unique position to create an environment of social inclusion where all students are respected and encouraged to meet their full potential (Koran 2015; Save the Children 2016). There is very little social work literature that addresses the right to quality education for refugee children through social inclusion. The micro/macro social work lens helps to facilitate a process of adaptation for refugee families to transition to a new culture, while respecting their traditions and addressing their challenges. Often, social workers are the bridge to advocate for children and families to work through their crises by their supportive counseling, case management, and policy advocacy functions in schools, communities, and political arena. Social workers play a key role in developing policies and programs that can influence social inclusion within educational systems.

The author explores strategies used in Hartford, CT, and suggests ways in which schools in urban settings, along with public officials, families, and communities help refugee students get a quality education. Enhancing the experiences of 
refugee children in the US schools is part of a broader effort to promote their social inclusion. Based on the literature and the experiences of Hartford, the author makes some suggestions that social workers, school educators, and the broader community work together to create a social inclusion environment to engage refugee children and families. This article recommends adaptations in the school system to ensure that refugee children have the human right to socially inclusive education so that they can live, grow, and develop their potential in a new culture.

\section{Education as a Human Right for Refugee Children}

The United Nations High Commission for Refugees recognizes education as a basic human right, enshrined in the 1986 Convention on the Rights of the Child (even though the US has not ratified the Convention on the Rights of the Child) and in the 1951 Refugee Convention (Anderson et al. 2010; UNHCR 2011). In 2015, the United Nations adopted Sustainable Development Goals (SDG, 2015-2030) which explicitly urge governments and civil societies to ensure inclusive and equitable quality education and to promote lifelong learning opportunities for all (United Nations Development Program, SDG \# 4). This fourth of 17 goals advocates for all girls and boys to receive complete free, fair, and quality primary and secondary education leading to relevant and effective learning outcomes.

Scholars support access to education as a human right (Aguilar and Retamal 2009; Havlvorsen 1990; Johnson 2010; McMillan 2011; Tomaskevsi 2005). Anderson et al. (2010) presents a body of work that demonstrate the critical role that education plays within a humanitarian setting. They also acknowledge that much needs to be done to translate this right into a reality. According to Anderson et al. (2010), children have rights to education (access to quality education), they have rights in education (a non-discriminatory environment based on respect and the best interest of the child), and they gain rights through education (the ability to make informed choices concerning their lives and to participate as citizens in the world). These rights are particularly critical in determining the success of refugee children in the USA.

\section{Social Inclusion}

Education is a way for refugees to become integrated in a new culture and is a process involving social inclusion through which they become "accepted in a society" (Thomas et al. 2015). Shared community spaces, such as schools, provide an opportunity for refugee children to meet other children and begin to form identities in the new culture (Thomas et al. 2015). Schools are a key institution in the provision of quality education and opportunities for social inclusion for children, families, and communities to work together. However, there has to be a public and political will to offset the negative impact of destabilization that is often a byproduct of the refugee experience.

Since 2010, at minimum 2932 refugees have been settled in Connecticut, with 452 in 2015 alone (cga.ct.gov). The state's Department of Social Services (DSS), through its Office of Community Services, is responsible for distributing federal funds for resettling refugees. The refugees are assigned by the State Department and state contracts to local agencies that provide social work case management and employment services to refugees. In FY 2007, 265 out of the 505 refugees who arrived in Connecticut were resettled in Hartford. Since half of the refugees resettled in USA are children (United Nations High Commission for Refugees 2015) and are enrolled in schools, a social inclusion and collaborative approach to education must be provided to help children "feel accepted" and free to learn.

For example, the state of Connecticut is a welcoming host to refugees and has created many social inclusion initiatives through cultural and political advocacy. The current political leadership has been very empathetic to the concerns of refugees. As the Syrian crisis continued to grow, Governor Dannel Malloy stated that we have "an obligation" to accept refugees, and is supportive of increasing the numbers coming into the state. This is in contrast to the 29 governors who have refused to host Syrian refugees. The same spirit of welcome is reflected by New Haven's Mayor, Toni Harp, who promises that her city will continue to welcome new residents from other countries and embrace their positive contributions (Berry 2015). Senator Chris Murphy of Connecticut has urged the USA to accept at least 50,000 refugees. In a similar vein, Senator Richard Blumenthal of Connecticut introduced a fourpoint plan that would limit delays and duplication of screenings in order to assist refugees seeking entrance to the USA (Berry 2015).

Beth Schiavino-Narvaez, the Hartford schools superintendent said "The people who come to our door are children and we have an obligation to educate every child that comes to us in the highest quality manner as possible. Whoever comes to us, we need to give them a great education" (Nix 2016). These welcoming expressions are an indication that Connecticut's leadership is ready and willing to reach out to refugees coming to the state, especially into the schools.

\section{Suggestions for a Social Inclusion Learning Environment}

How do schools begin to find ways to facilitate social inclusion? Sidhu and Taylor (2012) urge educators to regard refugee children as a unique, targeted group, and not to merely put 
them into a "homogenized migrant pool" (43). It is important to realize that schools are not equipped to deal with the unique and multifaceted challenges of refugee children. However, with some retooling and training for teachers and social workers, creative ways can be developed to include families and communities in a social inclusion learning environment. O'Rourke (2015) found that when Syrian refugee children had access to education, it provided them with the needed stability of daily structure and a sense of normalcy in their lives, as well as opportunities to develop the language and technical skills necessary for future employment. Similarly, Anderson et al. (Anderson et al. 2010) note that educational opportunities "mitigate the psychosocial impact of conflict and disasters by providing a sense of routine, stability, structure, and hope for the future" (p. 88).

According to McBrien (2005), a predominant theme in the literature is meeting the psychosocial well-being of refugee children. To help students adapt and thrive in a new learning environment and educational system is challenging. Many have to resume education that has been disrupted. Others are introduced to formal education for the first time and find it difficult to adjust to a rapid and foreign educational system (Clark-Kasimu 2015). The school environment can provide "a sense of safety, a sense of self, an adjustment to cultural expectations, and an acculturation process that allows them to maintain a connection to their native culture and language" (McBrien 2005, p. 339). Guerrero and Tinkler (2010) found that many refugee children viewed education as a path toward opportunity and freedom.

Strekalova and Hoot (2008) highlighted the need to educate teachers about the history and experiences of refugee children and how these inform their behaviors in school. Teachers can benefit from in-service training, strategies in teaching English as a Second Language, and education about the unique needs of refugee children. Szente, Hoot, and Tylor (2006) provided some practical ideas for teachers, which social workers and therapists can use to advance communication and trust. Young, newly arrived children can express basic emotions such as happiness, sadness, and anger through drawings, role plays, and sign language. Smiling, arts, and dance activities also help children communicate, creating safe spaces in schools.

Many refugee children and families express a feeling of social exclusion which refers to "the inability of an individual or population to fully participate in economic, social, and civic activities that directly affect their lives" (Thomas et al. 2014, p.233). It is vital to be aware that the educational system is the starting point for many refugee children entering the US. The level of support they receive after they arrive in the USA can determine their long-term outcomes. Carlson et al. (2012) described the disparate paths two Sudanese brothers took after their arrival in the US. One became a social worker, and the other died in an encounter with the police. The authors highlight the importance of the quality of care these brothers received after resettlement in the US and how that had an impact on their trajectories. Schools can be a critical positive point of contact for refugee children, especially when they feel welcomed. The institutions can serve as places of learning and growth while providing social contacts and guidance in navigating the complexities of a new culture. According to McBrien (2005), education is crucial for restoring social and emotional healing. Lerner (2012) recommended that schools adopt modes of instruction that are more inclusive and supportive. This would entail including, rather than excluding, elements of the refugee child's culture and language in the classroom.

\section{Hartford's Strategies Toward Education and Social Inclusion}

Having established that the state of Connecticut is open to receiving refugees, this article will narrow its examination to Hartford, a challenging urban environment where the city has found ways in which to involve schools and communities in social inclusion participatory strategies. Public schools in Hartford have a diverse population, including a large immigrant population. In school year 2013-2014, Hartford's classrooms were $31 \%$ black, $49 \%$ Hispanic, and $12 \%$ white, while $6 \%$ were defined as other (National Council on Teacher Quality). Other major cities in Connecticut, such as New Haven, Waterbury, and Bridgeport, reflect similar demographics. Since Hartford recognized that the school district is not homogenous, it has taken various social inclusion steps. For example, the Hartford school district has created a committee comprised of district policy, communication, family and community engagement teams to assist refugee families.

Each school in Hartford has a family resource center, and there is a welcoming center at the district administration building. The Welcome Center is part of the Office of Early Literacy and Parent Engagement (Hartford Public Schools 2016). The Center's aim is to provide district-wide support for all families, including English as a second language instruction for children and parents. These services address many of the needs that refugee families face when settling in Hartford and enrolling their children in the district schools. The Center works to engage families in their children's education. This is a particularly important effort for the families of refugee children, who often need help transitioning to the US educational system. The Center promotes family literacy through social workers' initiatives which include helping families assist their children with the school process, including reading with them, helping them with homework, and bringing them to the library (Hartford Public Schools 2016). In addition, the Adult Education Center in Hartford (AECH) offers ESL classes so that parents are more able to support 
their children and communicate with the schools (Hartford Public Schools 2016).

Catholic Charities, one of the 250 nonprofit organizations in Hartford, resettles the vast majority of refugees in the greater Hartford area. Catholic Charities of the Archdiocese of Hartford helps approximately 280 individuals and families from Somalia, Uganda, Burma, Iraq, Russia, Tunisia, Sudan, Cuba, Syria, Nepal, and Afghanistan resettle in the region every year. This number may reach 360 over the next year. Catholic Charities provides multicultural and multilingual social services that include housing, language instruction, school adjustment and tutorial assistance for children, and job training and placement. Realizing refugee needs within the educational system, the Hartford Public Schools and Catholic Charities are collaborating to obtain funding to address the children's additional educational and psychosocial needs (Nix 2016).

Catholic Charities coordinates social work case management services to ensure that families have guidance in all phases of the transition process. It continues to secure funding from the Connecticut Department of Education to hire translators and tutors in the schools to ensure language access for services. However, this demand is far greater than the resources available. In the interim, clusters of students who speak similar languages are enrolled in the same schools so bilingual teachers can be hired for 20 students or more. Similarly, the Connecticut Latino and Puerto Rican Affairs Commission has made similar recommendations, including distributing standardized tests in students' native languages. This not only serves to ease the transition to a new culture but also to assess the academic potential of refugee children in their native language without existing language barriers.

While public libraries in the US have a long history of providing a host of free resources aiding refugees' integration since 2010, the Hartford Public Library has been on the cutting edge of a new kind of civic integration program, We Belong Hartford. In addition to forming its own Advisory Board, which started in 2007, it served as the basis for the development of the Commission of Refugees and Immigration Affairs. The Hartford library offers citizenship and English as a second language class, online education, online high school education, math classes, and computer skills training. Other services include passport services, voter and election information, tax preparation assistance, and driver's education. In 2014, the Hartford Public Library became the first public library in the US to provide accredited citizenship and legal immigration services accredited by the Board of Immigration Appeals. In addition, many cultural programs and exhibits are designed to be inclusive and celebrate different cultures.

The Hartford Pulic Library's best social inclusion initiative is illustrated by its Cultural Navigator Program. Cultural navigators are volunteers from the host community, trained by social workers and graduate interns to help new refugees and immigrants adjust to life in Hartford. The cultural navigators serve as mentors, linking the new arrivals to services and institutions within the local community. This relationship is mutual with the cultural navigator and refugee learning about each other's culture, norms, and expectations. For further details of the Cultural Navigator Program, see Thomas et al. 2015.

In 2013, community dialogs in one Hartford neighborhood highlighted the need to increase opportunities for residents to gather, share ideas, and collectively solve problems. The Asylum Hill Neighborhood Association (ANHA), one of Hartford's Neighborhood Revitalization Zones, formed a welcoming committee in partnership with the Hartford Public Library. The welcoming committee consists of Asylum Hill residents and stakeholders from both the refugee and receiving communities. Through this committee, a series of facilitated community focus groups with on-site native language support were held in the fall of 2014 . More than 150 participants voiced what they felt were their community's greatest needs. Focus groups were organized by age and language groups: youth, Arabic and Middle Eastern languages, Bhutanese and Nepalese, African languages, and Karen with the assistance of social workers. The results of these meetings showed keen interest in and vision for a multicultural neighborhood center to address the needs and interests of all in the community (Hartford Public Library 2014). The work of social inclusion has continued through the Hartford Public Library's immigration and civic participation initiatives to include improved resident refugee connections to Asylum Hill, where many refugee families have resettled.

In 2014, the Hartford City Council passed a resolution to create the Commission on Refugee and Immigrant Affairs (CRIA), whose goals are as follows:

1. Create a means by which immigrant voices can be heard and understood, and to recognize and legitimize issues of importance to newcomers

2. Facilitate civic engagement among refugees and immigrants

3. Advise city government about the needs and status of our refugee and immigrant communities and advocate for their interests

4. Facilitate communication and understanding between and among the foreign born and native born residents of Hartford (CRIA, 2014)

The commission, including $70 \%$ refugee and immigrant members, creates connections among local immigrant community leaders and municipal, state, and federal government entities to promote social acceptance. The commission has advocated for refugees and undocumented residents by testifying before the city council, building coalitions, writing letters of support, drawing attention to arrival of undocumented 
children in the, and meeting their needs. Many of these policy advocacy efforts are led by social workers in key positions of leadership. In 2015, the commission created a survey to identify the needs of the refugee and immigrant communities in Hartford. Data is currently being collected, and the findings will help social service agencies and policymakers better understand the need of new refugee and immigrant arrivals.

\section{Discussion: Strategies to Enhance Social Inclusion to Promote Quality Education}

It is important that schools along with the community at large develop an infrastructure such as family resource centers, social service agencies, public libraries, neighborhood, and parents and teachers' associations and commissions that supports social inclusion for quality education. Based on existing literature and initiatives in Hartford, there is an expressed need to increase the public will to accept refugee children and families by elected officials in partnership with schools and communities. Despite the innovative efforts described above, the state of Connecticut has much more to do to help refugee children adjust in their new country and state. Because schools play a daily vital role in educating students, more attention needs to be placed on the development of actualizing each child's fullest potential for learning. The author recommends the following strategies to increase social inclusion in the schools: to enhance training for teachers and social workers in the areas of trauma, to increase outreach for parental involvement, and to develop a student peer mentoring initiative.

\section{Continuing Education for Teachers}

In the educational system, teachers spend the most time with refugee students and are in the best position to detect traumarelated behaviors. Shriberg (2010) notes that educators are not fully trained to screen and address the extensive needs of refugee students. Many refugee students who perform below grade level, pose disciplinary problems, or exhibit high-risk behaviors are viewed as discipline problems, rather than assessing them for Post Traumatic Stress Disorder (PTSD). In addition, the school community must be educated about the harms of bullying, especially for refugee children who are already traumatized. They must be able to identify, confront, and stop refugee bullying. Many schools have developed steps to prevent bullying and to create a space for children to learn without the fear of teasing, humiliation or assault. The state of Connecticut under Public Act 11-232 (2011), An Act Concerning the Strengthening of School Bullying Laws, was signed into law by Governor Malloy in 2011. This comprehensive law, written by a social worker and a legal team, requires all schools to have a clear anti-bullying policy. One of the recommended, but not required, interventions described in the Act, however, is the "inclusion of grade-appropriate bullying education and prevention curricula in kindergarten through high school" (Public Act 11-232, 2011). Teachers need to collaborate with social workers, guidance counselors and other mental health providers to specifically help screen children suffering and coping with trauma.

Shriberg (2010) reports that $96 \%$ of teachers surveyed had no training at all in how to educate refugee students; $50 \%$ of them reported interest in receiving information about the culture, history, politics, and education systems of the countries of origins. Almost all of those surveyed wanted to know best practices for teaching refugee students, including practical teaching techniques and adaptations of curriculum. Teachers need guidance on how to best educate refugee students and how to gain access to the many resources available from other similarly situated educators throughout the world. Shriberg points out that "educators may not be fully aware of the unique and creative strategies and coping skills refugee children possess that can help them attain success as students" ( $p$. 5). Many of the Professional Development programs that offer training in "best practices with refugee children" come from the ESL arena that utilize the strengths of the refugee students (personal communication, Louise Harmon, 06-02-2016). Training teachers about screening for trauma, enhancing cultural competency, understanding the implications of these issues for developing curriculum, and working with other professionals to embrace the strengths and challenges of refugee students are necessary action steps to ensure quality education through social inclusion approaches.

\section{Continuing Education for School Social Workers}

Continuing education and training for school social workers is needed to increase their capacity in trauma-related counseling, advocacy, and policy development. These social workers can provide trauma-informed practice and help students develop their ability to manage distress and to enhance their capacity for increased daily functioning (Knight 2014). According to Weine (2008), service providers in the refugee field need to find techniques that help refugees of war trauma, those traumatized by forced migration, as well as those affected by other contextual variables, such as discrimination, or gender and power differentials. He recommends that "trauma-related" services should include a range of diagnosable disorders, such as depression, anxiety, and school problems. While traumarelated services are already covered in social work training, school districts need to provide a continuum of training. The training needs to include trauma-informed practice that addresses the unique needs of different groups/subgroups and takes into account the contextual factors of each refugee's experience. White (2010) stresses the importance of training 
mental health workers in effective methods to treat clients who are traumatized, as well as training in secondary traumatic stress disorders for themselves. It is important that social workers avoid suffering from compassion fatigue and remain helpful to their clients.

\section{Outreach to Refugee Families to Engage in the School}

To provide awareness and opportunities to reach out to refugee parents and to encourage involvement with their children's education are important. The research consistently demonstrates that the academic achievement of all students whose parents were involved in their education was significantly higher than those whose parents were not (Jeynes 2005). The types of involvement that had the most impact were parents reading with their children, communicating with teachers, attending school events, being active in the PTA, volunteering at school, and supervising school work at home (Bridging Refugee Youth and Children Services (BYRCS) 2007). For parents of refugee children, research shows that additional barriers exist. These include transportation; time off from work; having no childcare; different notions of family privacy; embarrassment about their child's performance in school; lack of language proficiency, and an overall misunderstanding of how American schools operate and what the parental role is in relationship to the educational system (Weine 2008). Such factors make educational inclusion efforts for refugee children more complex.

Golan and Peterson (2002) observe that parental involvement is not commonly sought in school systems in other countries and that immigrant parents may need to be made aware of their responsibilities and rights to be involved in their children's education. These parents also may have to be trained in behaviors that support their children's education, including frequent communication with their children's teachers, reading to their children, praising children for doing well in school, and reviewing homework. Immigrant parents may need to have educational norms communicated to them-grading, testing, attendance requirements, homework policies, parent/ teacher conferences, and the importance of extra-curricular activities (Golan and Peterson, 2002). In many cultures, teachers are revered and are treated as experts in their field. In these societies, it is often disrespectful to question a teacher or interfere in their work in any way and in many countries, parents rarely visit their children's schools or talk with their teachers" (BRYCS 2007).

BRYCS (2007) makes some of the following recommendations that could assist in involving the parents of refugee children: hire an interpreter, or find one from an NGO, translate as many documents as possible, and provide interpretation at school events rather than burdening children with this task.
To offset some of the barriers, BRYCS recommends offering to provide translators for any meeting with refugee parents; choosing vocabulary that is easy to translate; and encouraging parents to read in their native language. School personnel, whenever possible, should speak to parents in person or by phone, reducing the amount of memos sent home.

Since transportation and child care can be barriers for many refugee families, schools can help by providing these services where there are school events; and be flexible about when meeting times are scheduled. Another outreach initiative that a refugee parental involvement plan (BRYCS) might implement is to create cultural liaison programs that bridge the gap between families and the school. These programs provide orientation for refugee parents to explain the norms of the school; build trust with refugee parents before trying to engage them directly about their child's education; appoint some ambassador parents from the Parents Association to ensure that all PTA activities include refugee parents.

\section{Peer Mentoring Program}

A peer mentoring program to promote communication between refugee students and other students in the school will enhance collaboration, communication and deeper understanding of diversity. A program such as peer mentoring will enhance assimilation of refugee students by using a peer mentoring system, pairing up a refugee student with a US born student as a "buddy" (Mtethwa-Sommers and Kisiera, 2015). The peer mentor should volunteer to be a mentor, and would help the refugee student practice English, do homework, teach him or her the norms of the school, share a table in a lunchroom, introduce him or her to extra-curricular activities, and protect him or her from any bullying (Mtethwa-Sommers and Kisiera, 2015). After the first refugee students have begun to acculturate, the older refugee students would also make excellent peer partners for new incoming refugees, particularly when the incoming students do not know English. MENTOR (2009) also stresses that bilingual and bicultural mentors offer unique and promising opportunities for non-English speaking immigrant youth. It helps by easing the transition into a new culture, helping to learn English, and gaining a role model that can help create a bicultural/ bilingual identity.

\section{Conclusion}

Children have a right to quality education and to actively participate in their learning in a safe and inclusive environment. As indicated earlier, the traumatic journey of resettlement can be offset by welcoming communities, including schools that are ready to meet the children's special needs. 
In the current climate, schools can help integrate newly arriving immigrants and refugees to live, grow, and develop their potential to productively contribute to society. Because of their influence in children's lives, schools are in the position to create inclusive spaces for refugee children and their families. These children are often marginalized in schools because of cultural and language barriers. Schools must find ways to include all members of the refugee child's life by engaging parents and their supportive communities. It is essential to recognize that refugee families want their children to advance, but might lack the capacity to negotiate complex educational systems in a foreign environment. When schools begin fostering social inclusion, refugees begin to find a place of support to rebuild their lives.

Social inclusion is at the heart of a human rights perspective and woven into the fabric of social work practice. Social workers have a unique opportunity to use trauma-informed practice, to work with refugees regarding psychosocial issues related to trauma, transitions, and resettlement. School social workers can help with issues related to communication and mental health, facilitate positive interactions between teachers and students, and reach out to families to include them in their children's education. Social workers can begin to develop best practice models based on research that includes micro and macro perspectives. Further research in social work about refugees' experiences, needs, and insights is needed to advance schools' initiatives around social inclusion on national and international levels.

\section{References}

Aguilar, P., \& Retamal, G. (2009). Protective environments and quality education in humanitarian contexts. International Journal of Education Development, 29, 3-16.

Anderson, A., Hoffman, J., \& Hyll-Larsen, P. (2010). The right to education in emergencies, journal of education for children in emergencies. Legal Studies, 2(1), 84-126.

Bacakova, M. (2011). Developing inclusive educational practices for refugee children in the Czech Republic. Intercultural Education, 22(2), $163-175$.

Berry, S. (2015, November 17). Connecticut Gov. Malloy: "We have an obligation" to accept refugees. Breitbart News Network. Retrieved from www.breitbart.com/big-government/2015/11/17/connecticutgov-dannel-malloy-obligation-accept-refugees.

Bridging Refugee Youth \&Children Services (BYRCS) (Spring 2007). Involving refugee parents in their children's educations. Retrieved from http://www.brycs.org/documents/upload/brycs spotspring2007-2.pdf.

Carlson, B. E., Cacciatore, J., \& Klimek, B. (2012). A risk and resilience perspective on unaccompanied refugee minors. Social Work, 57(3), 259-269.

Clark-Kasimu, N. (2015). Serving refugee students and unaccompanied minors: more than just learning English. Annenberg Institute for School Reform, 41, 20-25.
Connecticut State Department of Education. (2012). Immigrant Children and Youth Education Grant Application. Hartford, CT: Author. Retrieved from http://www.sde.ct.gov/sde/lib/sde/pdf/rfp/rfp136 immigrant_children_youth_ed12_13.pdf.

Fazel, M., \& Stein, A. (2002). The mental health of refugee children. Archives of Disease in Childhood, 87(5), 366-370.

Golan, S., \& Petersen, D. (2002). Promoting involvement of recent immigrant families in their children's education. Retrieved from http://www.hfrp.org/family-involvement/publicationsresources/promotinginvolvement-of-recent-immigrant-families-intheir-children-s-education. Accessed 6 September 2016.

Guerrero, A. L., \& Tinkler, T. (2010). Refugee and displaced youth negotiating imagined and lived identities in a photography-based educational project in the United States and Colombia. Anthropology \& Education Quarterly, 41(1), 55-74.

Hart, R. (2009). Child refugees, trauma and education: interactionist considerations on social and emotional needs and development. Educational Psychology in Practice, 25(4), 351-368.

Hartford, CT Code of Ordinances. (2014). Commission on refugee and immigrant affairs. Retrieved from http://www.hartford. gov/images/mayors/BoardsAndCommissions/RefugeeAndImmigrant Affairs/Muni-Code-CRIA.pdf. Accessed 10 November 2016.

Hartford Public Library. (2014). Multicultural Focus Group Report. Hartford, CT: Author.

Hartford Public Schools. (2016). The welcome center: who we are. Retrieved from www.hartfordschools.org/familyresources/welcome-center.

Havlvorsen, K. (1990). Notes on the realization of the human right to education. Human Rights Quarterly, 12(3), 341-364.

Human Rights Watch. (2015). Turkey: 400,000 Syrian children not in school. Retrieved from www.hrw.org/news/2015/11/08/turkey400000-syrian-children-not-school.

Jeynes, W. (2005). Parental involvement and student achievement: a meta-analysis. Harvard Family Research Project. Retrieved from http://www.hfrp.org/publications-resources/browse-ourpublications/parental-involvement-and-student-achievement-ameta-analysis.

Johnson, R. (2010). The child's right to an education: 'concensus-minusone? International Journal of Children's Rights, 18, 185-216.

Knight, C. (2014). Trauma-informed social work practice: practice considerations and challenges. Clinical Social Work Journal. 43(1).

Koran, L. (2015, November 17). How do Syrian refugees get into the? Explaining the process. $C N N$. Retrieved from www.cnn. com/2015/11/16/politics/syrian-refugees-u-s-applicantsexplainer.

Kugler, E. (2009). Partnering with parents and families to support immigrant and refugee children at school. Center for Health and Health Care in School, Issue Brief \# 2.

Lerner, A. B. (2012). The educational resettlement of refugee children: examining several theoretical approaches. Multicultural Education, 20(1), 9-14.

Lyons, K., \& Huegler, N. (2012). Social exclusion and inclusion. In L. M. Healy \& R. J. Link (Eds.), Handbook of international social work (pp. 37-43). New York: Oxford University Press.

McBrien, J. L. (2005). Educational needs and barriers for refugee students in the United States: a review of the literature. Review of Educational Research, 75(3), 329-364.

McMillan, L. K. (2011). What is a right? Two variations for interpreting the right to education. International Review of Education, 5, 531545.

Meda, L., Sookrajh, R., \& Maharaj, B. (2012). Refugee children in South Africa: access and challenges to achieving universal primary education. African Education Review, 9(1), S152-S168.

MENTOR (2009). Mentoring immigrant \& refugee youth: a toolkit for program co-ordinators. Retrieved from http://www.mentoring. org/downloads/mentoring_1197.pdf. 
Mtethwa-Sommers, S., \& Kisiera, O. (2015). Listening to students from refugee backgrounds: Lessons for educational professionals. Retrieved from http://www.urbanedjournal.org/archive/volume-12issue-1-spring-2015/listening-students-refugee-backgroundslessons-education-profe. Accessed 8 September 2016.

Nix, N (2016, January 6). The schools taking in Syrian refugees. Retrieved from http://ww wheatlantic. com/education/archive/2016/01/connecticut-schools-syrianrefugees/421968.

O'Rourke, J. (2015). Education for Syrian refugees: the failure of secondgeneration human rights during extraordinary crises. Albany Law Review, 78(2), 711-738.

Save the Children. (2016). Refugee children crisis. Retrieved from www.savethechildren.org/site/c.8rKLIXMGIpI4E/b.9311443 /k.5C24/Refugee Children_Crisis.htm

Shriberg, J. (2010). Advancing teacher development in Colorado Refugee Education Programs. University of Denver. Retrieved from http://www.springinstitute.org/Files/executivereporttdrproject.pdf. Accessed 6 September 2016.

Sidhu, R., \& Taylor, S. (2012). Supporting refugee students in schools: what constitutes inclusive education? International Journal of Inclusive Education, 16(1), 39-56.

Sirin, S.R. \& Rogers-Sirin, L. (2015). The educational and mental health needs of Syrian refugee children. Migration Policy Institute.

Strekalova, E., \& Hoot, J. L. (2008). What is special about special needs of refugee children?: guidelines for teachers. Multicultural Education, 16(1), 21-24.

Szente, J., \& Hoot, J. (2006). Exploring the needs of refugee children in our schools. In L. D. Adams \& A. Kirova (Eds.), Global migration and education: school, children, and families (pp. 219-236). Mahway, NJ: Lawrence Erlbaum Associates.

The World Bank. (2013). Social inclusion. Retrieved from www. worldbank.org/en/topic/socialdevelopment/brief/social-inclusion.
Thomas, R. L., Chiarelli-Helminiak, C., \& Ferraj, B. (2014). A case study in immigrant civic engagement research: linking human rights to social work education. In K. R. Libal, S. M. Berthold, R. L. Thomas, \& L. M. Healy (Eds.), Advancing human rights in social work education (pp. 231-247). Alexandria, VA: CSWE Press.

Thomas, R. L., Chiarelli-Helminiak, C. M., Ferraj, B., \& Barrette, K. (2015). Building relationships and facilitating immigrant community integration: an evaluation of a cultural navigator program. Evaluation and Program Planning, 55, 77-84.

Tomaskevsi, K. (2005). Human rights obligations in education: the 4 A;s scheme (1st ed.). Nigmegan: Wolf Legal Publishers.

UNHCR (2011). UNHCR resettlement handbook. Retrieved from www. unhcr.org/46f7c0ee2.pdf.

United Nations. (1995). The Copenhagen Declaration and Programme of Action: World Summit for Social Development. Retrieved from ww.un.org/esa/socdev/wssd/text-version/agreements/poach4.htm

United Nations. (2016). Refugees. Retrieved from www.unhcr. org/pages/49c3646c125.html.

United Nations Development Program (2015). Sustainable development goals. Retrieved from undp.org/content/undp/en/home/ sdgoverview/post-2015-development-agenda/goal-4.htm.

United Nations High Commission for Refugees. (2015). UNHCR global trends: forced displacement in 2014. Retrieved from unhcr.org/ 556725e69.html.

Weine, S. (2008). Family roles in refugee youth resettlement from a prevention perspective. Child Adolescent Psychiatric Clinical North American, 17(3), 515-vii. Retrieved from http://www.ncbi. nlm.nih.gov/pmc/articles/PMC3414421.

White, G. (2010). Trauma treatment training for Bosnian and Croatian mental health workers. American Journal of Orthopsychiatry, 68(1), $58-62$. 